\title{
Functional interplay between YY1 and CARM1 promotes oral carcinogenesis
}

\author{
Amit K. Behera ${ }^{1}$, Manoj Kumar ${ }^{1}$, Muthu K. Shanmugam², Aditya Bhattacharya ${ }^{1}$, \\ Vinay J. Rao ${ }^{1}$, Akshay Bhat ${ }^{1}$, Madavan Vasudevan ${ }^{3}$, Kodaganur S. Gopinath ${ }^{4}$, \\ Azeem Mohiyuddin ${ }^{5,6,7}$, Anupam Chatterjee ${ }^{8}$, Gautam Sethi ${ }^{2}$ and Tapas K. Kundu ${ }^{1}$ \\ ${ }^{1}$ Transcription and Disease Laboratory, Molecular Biology and Genetics Unit, Jawaharlal Nehru Centre for Advanced Scientific \\ Research, Bangalore 560064, India \\ ${ }^{2}$ Department of Pharmacology, Yong Loo Lin School of Medicine, National University of Singapore, Singapore 117600, Singapore \\ ${ }^{3}$ Bionivid Technology Private Limited, Kasturi Nagar, Bangalore 560043, India \\ ${ }^{4}$ Department of Surgical Oncology, HCG Bangalore Institute of Oncology, Bangalore 560027, India \\ ${ }^{5}$ Department of Pathology, Sri Devaraj Urs Academy of Higher Education and Research Center, Kolar, Bangalore 563101, \\ India \\ ${ }^{6}$ Department of Ear, Nose and Throat, Sri Devaraj Urs Academy of Higher Education and Research Center, Kolar, Bangalore \\ 563101, India \\ ${ }^{7}$ Department of Head and Neck Surgery, Sri Devaraj Urs Academy of Higher Education and Research Center, Kolar, Bangalore \\ 563101, India \\ ${ }^{8}$ Department of Biotechnology and Bioinformatics, North-Eastern Hill University, Shillong, Meghalaya 793022, India \\ Correspondence to: Tapas K. Kundu, email: tapas@jncasr.ac.in \\ Gautam Sethi, email: phcgs@nus.edu.sg \\ Keywords: oral cancer; oncogene; YY1; CARM1; arginine methylation
}

Received: January 19, $2019 \quad$ Accepted: May 13, $2019 \quad$ Published: June 04, 2019

Copyright: Behera et al. This is an open-access article distributed under the terms of the Creative Commons Attribution License 3.0 (CC BY 3.0), which permits unrestricted use, distribution, and reproduction in any medium, provided the original author and source are credited.

\section{ABSTRACT}

Coactivator associated arginine methyltransferase 1 (CARM1) has been functionally implicated in maintenance of pluripotency, cellular differentiation and tumorigenesis; where it plays regulatory roles by virtue of its ability to coactivate transcription as well as to modulate protein function as an arginine methyltransferase. Previous studies establish an oncogenic function of CARM1 in the context of colorectal and breast cancer, which correlate to its overexpressed condition. However, the mechanism behind its deregulated expression in the context of cancer has not been addressed before. In the present study we uncover an oncogenic function of CARM1 in the context of oral cancer, where it was found to be overexpressed. We also identify YY1 to be a positive regulator of CARM1 gene promoter, where silencing of YY1 in oral cancer cell line could lead to reduction in expression of CARM1. In this context, YY1 showed concomitant overexpression in oral cancer patient samples compared to adjacent normal tissue. Cell line based experiments as well as xenograft study revealed pro-neoplastic functions of YY1 in oral cancer. Transcriptomics analysis as well as qRT-PCR validation clearly indicated pro-proliferative, pro-angiogenic and prometastatic role of YY1 in oral cancer. We also show that YY1 is a substrate of CARM1 mediated arginine methylation, where the latter could coactivate YY1 mediated reporter gene activation in vivo. Taken together, CARM1 and YY1 were found to regulate each other in a positive feedback loop to facilitate oral cancer progression. 


\section{INTRODUCTION}

YY1 regulates expression of a wide range of genes involved in multitude of cellular processes such as proliferation, differentiation and apoptosis [1]. YY1 is known to integrate several bio-molecular pathways in cell; therefore its role in patho-physiological manifestation of different human diseases, especially in cancer, has been extensively studied [2]. Its expression has been correlated with malignant phenotype of tumor with prognostic significance in several cancer types [3, 4]. However, in certain forms of cancer, YY1 expression shows unfavorable association with tumorigenesis [5]. Existence of such conflicting scientific evidences indicates a very complex network of genes regulated by YY1, where fine balance among them in different conditions can dictate the outcome $[6,7]$.

Several studies suggest both oncogenic and tumor suppressor function of YY1 in breast cancer progression. According to one report, YY1 is overexpressed in breast cancer tissue and its knock-down in breast cancer cell lines leads to reduction of clonogenicity, migration and invasion of cells. At molecular level, YY1 was found to exert oncogenic function via negative regulation of p27 expression [8]. Another study documents observations which are completely opposite in nature. According to this study YY1 is able to transactivate expression of tumor suppressor BRCA1 via promoter regulation. Ectopic overexpression of YY1 in breast cancer cell line MDA-MB-231 led to cell cycle arrest and reduced cellular growth in vitro and in vivo. Clinical investigation also showed negligible expression status of YY1 in breast tumor tissue compared to normal counterpart; which is in direct contradiction to the observation made in the previous study [9]. Tumor suppressor role of YY1 also has been shown in the context of pancreatic ductal adenocarcinoma (PDAC), where YY1 overexpression was found to suppress proliferation, migration, invasion and metastasis of PDAC cells [10-12]. Substantial overexpression of YY1 has been observed in gastro-intestinal cancers [13]. YY1 was found to be overexpressed in esophageal squamous cell carcinoma (ESCC) and its expression correlated with progression and invasiveness of esophageal cancer [14]. YY1 has been found to be overexpressed in melanoma compared to benign nevi and normal tissue control with positive correlation with metastasis and tumor stage [15]. Silencing of YY1 was shown to inhibit proliferation, migration and invasion of melanoma cells. The tumorigenic potential of YY1 in colon cancer has been demonstrated with both overexpression and knock-down experiments in colorectal cancer cell lines such as HCT116, LOVO and DLD [16]. Silencing of YY1 resulted in reduced proliferation and induction of apoptosis, whereas overexpression enhanced proliferation and inhibited apoptosis of colorectal cancer cells. The growth of xenograft tumor tissue in nude mice responded accordingly. At molecular level, YY1 mainly inhibited p53 and activated Wnt signaling pathway to promote colon carcinogenesis [16]. There are multiple reports which unequivocally show upregulation of YY1 in several prostate cancer cell lines as well as prostatic neoplasia of patients $[17,18]$. YY1 positively regulates expression of PSCA (Prostate stem cell antigen) via which it is believed to contribute to disease progression and metastasis in prostate cancer [19]. Additionally, YY1 represses expression of death receptor 5 (DR5) and Fas, thereby conferring resistance to TRAIL and FasL induced apoptosis in prostate cancer cells [20-22]. Similar investigations show upregulated expression of YY1 in several other cancer types such as lung cancer, ovarian cancer, cervical cancer, liver cancer, bladder cancer, bone cancer, skin cancer and in a few types of non-solid tumors such as acute myeloid leukemia (AML), follicular lymphoma (FL) and diffuse large B-cell lymphoma (DLBCL) [3, 4]. However, there are no reports on the expression status and functional properties of YY1 in the context of oral cancer. In this study we demonstrate overexpression status of YY1 with oncogenic functions in oral cancer. We also identify CARM1 (Coactivator associated arginine methyltransferase 1) as a coactivator of YY1 mediated transcription in cellulo.

CARM1 has been found to be overexpressed in several cancer types such as breast cancer, colorectal cancer and prostate cancer, where it exhibits oncogenic properties [23-29]. However, the role of CARM1 in progression of oral carcinogenesis has not been explored before. Oral cancer is one of the major causes of mortality in several countries of the world [30,31]. It has gained huge scientific interest in last decade as a major health issue in Melanesia, South-central Asia and Central and Eastern Europe [30]. Several studies carried out by multiple groups have established the correlation between etiology and clinical manifestation of oral cancer, facilitating development of preventive measures [32, 33]. However, extensive molecular biology research would be necessary to identify different oncogenic candidates so that chemotherapy specific for oral cancer could be designed. Keeping in mind the need of the hour, we put our effort in the present study to elucidate the molecular function of CARM1, a prospective oncogenic candidate and a probable therapeutic target in the context of oral cancer. In this report, we uncover interplay between YY1 and CARM1 that promotes oral carcinogenesis.

\section{RESULTS}

\section{CARM1 is overexpressed in oral cancer}

We were interested to investigate the expression status of CARM1 in oral cancer patient samples. Immunohistochemistry analysis using CARM1 specific antibody revealed significant upregulation of CARM1 
expression in oral cancer tumor tissue compared to normal counterpart (Figure 1A). The H-scoring values of immunostaining for 26 pairs of oral cancer patient samples have been compared in Figure 1B. Immunohistochemistry experiment with H3R17me2a modification also indicated higher prevalence of the mark in tumor samples in comparison with adjacent normal tissue (Supplementary Figure 1A, 1B). As asymmetric dimethylation of H3R17 is specifically mediated by CARM1 enzyme among the PRMT family members, its higher prevalence justifiably could be attributed to CARM1 over-expression. The clinicopathological information has been summarized in Supplementary Table 1 . We wanted to further investigate the driving force behind transcriptional upregulation of CARM1 in oral cancer. The genome wide transcription factor enrichment profile from ENCODE repository revealed a few prospective $\mathrm{TF}$ candidates for regulation of CARM1 expression in oral cancer such as E2F4, CTCF, YY1 and cMyc etc. (Figure 1C). Bioinformatic prediction for the presence of binding sites of different transcription factors on CARM1 promoter by Consite also confirmed the presence of motifs responsive to above TFs (data not shown). Initial screening with above mentioned transcription factors in regulating CARM1 promoter driven luciferase reporter gene expression revealed a positive regulation of CARM1 promoter by $\mathrm{YY} 1$, where transfection of increasing amounts of pcDNA3-HA-YY1 in HEK293T cells enhanced CARM1 promoter activity in a dose dependent manner (Figure 1D).

\section{YY1 is overexpressed in oral cancer and regulates CARM1 expression}

As our results clearly suggest that YY1 positively regulates CARM1 promoter and CARM1 is highly overexpressed in oral cancer patient samples, we wanted to find out whether CARM1 overexpression is caused by upregulation of YY1 in the context of oral cancer. To assess expression status of YY1 in oral cancer, immunohistochemistry (IHC) was performed using YY1 specific antibody. The representative IHC images have been shown in Figure 1E. H-scoring with 27 pairs of oral cancer patient samples revealed significant upregulation of YY1 in oral cancer tumor tissue compared to adjacent normal tissue (Figure 1F). A positive correlation between $\mathrm{H}$-scores for CARM1 and YY1 expression in oral tumor samples was observed (Figure 1G). This finding indicates that CARM1 overexpression could be attributed to have occurred partly due to upregulated expression of YY1. Furthermore, we performed mRNA expression analysis with knock-down of YY1 in a grade III, oral cancer cell line, AW8507. The inducible knock-down of YY1 in AW8507_Tet-ON-shYY1 cells with Doxycycline treatment was found to lead to reduction in expression of CARM1, indicating transcriptional regulation by YY1 in the context of oral cancer (Figure 2A-2C). In order to transcriptionally upregulate CARM1 gene expression, YY1 must bind to the responsive elements on the CARM1 promoter. Consite, an online bioinformatic tool, identified multiple putative binding sites of YY1 on human CARM1 promoter with $80 \%$ cut off score (data not shown). One of the high scoring predicted binding sites was selected for validation and oligonucleotide containing YY1 responsive elements was used to perform in vitro EMSA (Figure 2D). His-YY1 formed a complex with radiolabelled oligonucleotide that showed decreased intensity when unlabelled probe was allowed to compete for interaction. Supershift of proteinDNA complex was observed in the presence of antibody against the His-tag, further indicating specificity of the complex (Figure 2E). Chromatin immunoprecipitation assay with YY1 antibody suggested recruitment of YY1 on CARM1 promoter, which showed decrease in enrichment upon inducible silencing of YY1 in AW8507_Tet-ONshYY1 cells (Figure 2F). Taken together, these data prove that YY1 positively regulates CARM1 expression and is at least partly responsible for the overexpression of CARM1 in oral cancer patient tumors.

We also analyzed RNA-seq data available in TCGA (The Cancer Genome Atlas) to determine any possible correlations in RNA expression of CARM1 and YY1 in different cancer types. The expression patterns of the two genes were found to vary across different tumor types (Supplementary Figures 2 and 3). Analysis of correlation status across the different tumor types revealed that the two genes do not follow any particular pattern universally. It was seen that most cancer types, for the particular cohorts showed negative or no correlation, while only ESO and TGCT showed a positive correlation in the expression pattern (Supplementary Figure 4, Supplementary Table 2). Given that only RNA expression data has been compared, and not the protein profiles, it is also possible that post-translational modifications may play a role in protein stability and that the correlation data in such cases may change.

\section{YY1 and CARM1 exhibit oncogenic function in oral cancer}

In order to understand the functional significance of YY1 overexpression in oral cancer, different tumorigenic assays were performed in AW8507_Tet-ON-shYY1 stable cell line with inducible silencing of YY1 expression. MTT assay was performed to understand the contribution of YY1 in cellular proliferation. AW8507 cells showed reduced proliferation when YY1 expression was silenced, indicating a pro-proliferative role of YY1 in oral cancer (Figure 3A). Similarly, AW8507 cells with inducible knock-down of YY1 showed slower migration in in vitro wound healing assay (Figure 3B). In clonogenic assay AW8507 cells formed fewer and smaller colonies under YY1 silencing conditions, indicating a necessity of YY1 for clonal propagation of oral cancer cells (Figure 3C, $3 \mathrm{D})$. The smaller colonies imply reduction in proliferation 
ability of cells, further confirming MTT assay results. The findings on wound healing assay and colony formation assay indicate a positive role of YY1 as a prometastatic regulator, which might favor EMT (Epithelial to mesenchymal transition) in vivo.

Tumorigenic potential of CARM1 was also assessed with inducible silencing of CARM1 in AW8507 cells (Figure 4A-4C). MTT assay was performed to assess proliferation ability of AW8507_Tet-ON-shCARM1 stable cells with inducible silencing of CARM1 expression. However, no change in proliferation was observed in cells with reduced CARM1 expression compared with control cells (Figure 4D), indicating a non-essential role for CARM1 in proliferation. Similarly, in vitro wound healing assay and clonogenic assays were performed with inducible knock-down of CARM1 expression. The effect of inducible silencing of CARM1 on migration potential of AW8507_Tet-ON-shCARM1 cells was significant
(Figure 4E). In clonogenic assay, the colony establishment capacity was adversely affected in absence of CARM1 as reflected by the difference in colony number (Figure 4F, 4G). However, the colony size was similar in nature, indicating similar proliferation rates irrespective of expression status of CARM1 in AW8507 cells, further confirming the results of MTT assay.

\section{Determination of gene expression profile modulated by YY1 in oral carcinogenesis}

From the above experiments, YY1 was revealed to act as an oncogene in the context of oral cancer. We wanted to investigate and determine the gene signature influenced by YY1 to contribute to oral cancer progression. Therefore, microarray based transcriptomic analysis was performed to identify the genes directly or indirectly influenced by YY1 in oral cancer. The differential gene expression data showed
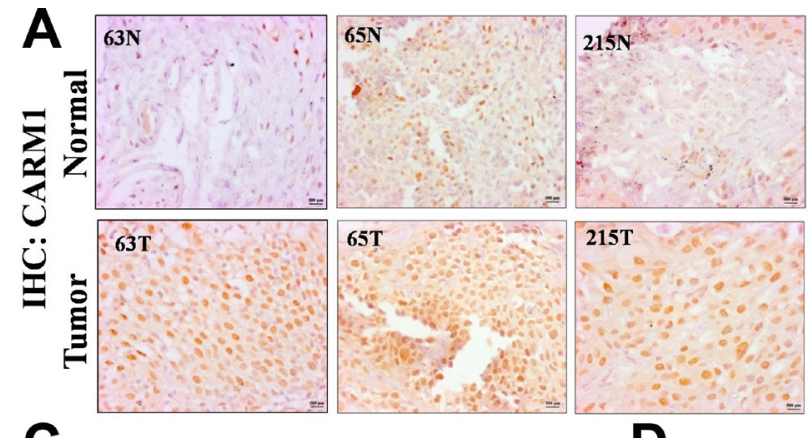

D

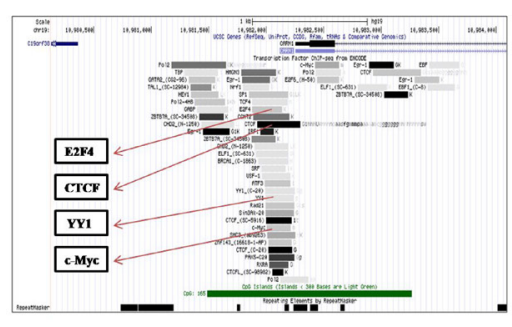

E
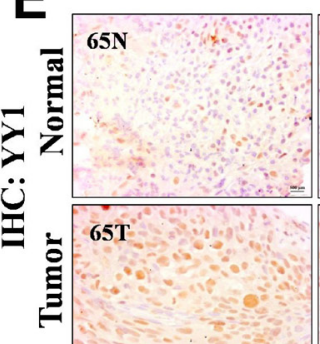

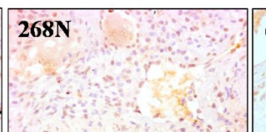

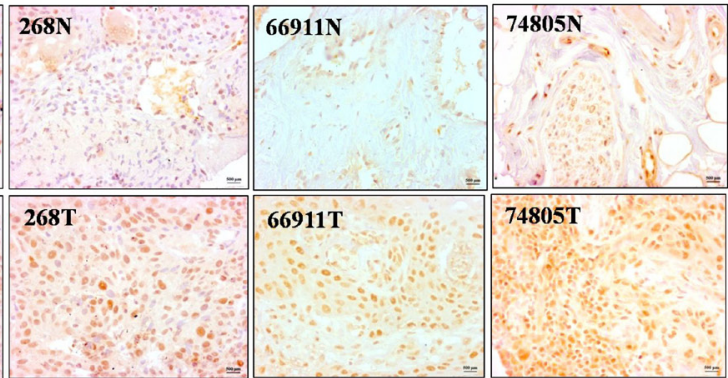

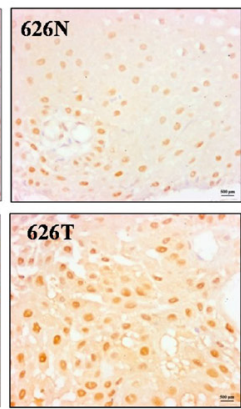

Luciferase Assay
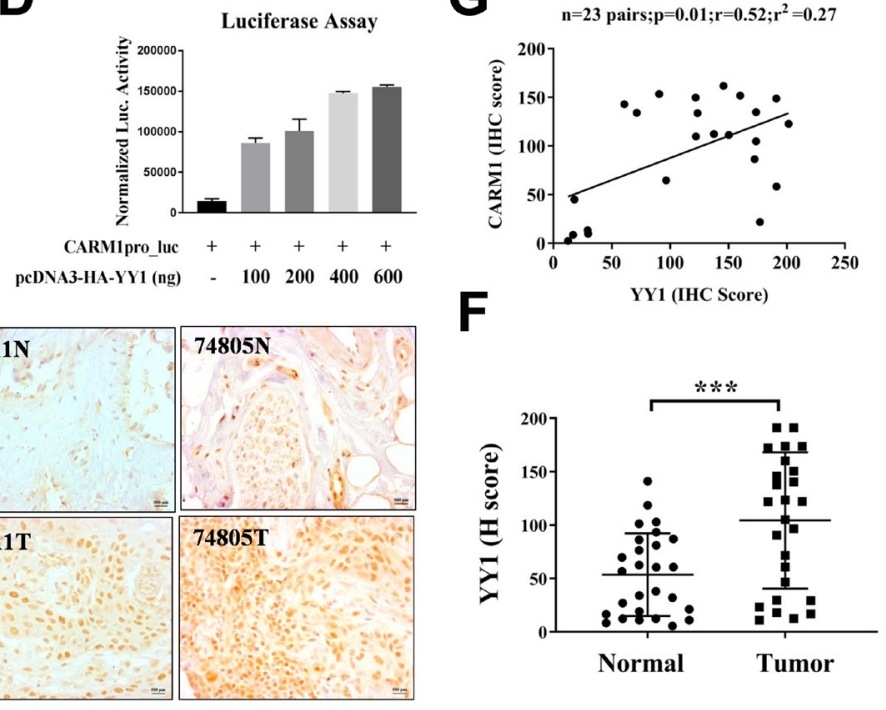

Figure 1: CARM1 and YY1 are overexpressed in oral cancer patient tumor tissue. (A) Representative immunohistochemistry images of paired oral cancer patient samples stained with CARM1 antibody. The numbers on images represent patient ID (e.g., 63, 65, 215 and 626). Image scale: $500 \mu \mathrm{m}$. (B) H-scoring for CARM1 staining in oral cancer patient tumor tissue compared to adjacent normal tissue $\left(n=26\right.$; Student's $t$-test: $\left.{ }^{* * * *} p<0.0001\right)$. (C) Snapshot of Genome browser from ENCODE to show enrichment of different transcription factors on CARM1 promoter. Highlighted are E2F4, CTCF, YY1 and c-Myc. (D) Luciferase assay with transfection of increasing amounts of pcDNA3-HA-YY1 (e.g., 100ng, 200ng, 400ng, 600ng) in HEK293T cells in a dose dependent manner $(n=2)$. (E) Representative immunohistochemistry images of paired oral cancer patient samples stained with YY1 antibody. The numbers on images represent patient ID (e.g., 65, 268, 66911 and 74805). Image scale: $500 \mu \mathrm{m}$. (F) H-scoring for YY1 staining in oral cancer patient tumor tissue compared to adjacent normal tissue $\left(n=27\right.$ and $\left.{ }^{* * *} p<0.001\right)$. (G) Correlation analysis of H-scores of CARM1 and YY1 immunohistochemistry in oral tumor tissues $\left(n=23, p=0.01, r=0.52, r^{2}=0.27\right)$. 
up-regulation of 236 transcripts and down-regulation of 510 transcripts with a fold change of $\geq 1.5$ and $p$ value of $\leq 0.05$. The hierarchical clustering of differentially expressed genes from biological duplicates of samples has been represented in heat map form in Figure 5A.

Biological pathway enrichment analysis with differentially expressed genes revealed various categories related to proliferation, metabolism, hypoxia and senescence, which have been represented in the form of a molecular network in Figure 5B. Salient features of the network are as follows: (1) Inducible knock-down of YY1 led to suppression of mitogenic pathways such as TGF signaling (both TGFA and TGFB) and c-Myc pathway, which indicates role of YY1 in proliferation of oral cancer cells. (2) Inducible knock-down of YY1 resulted in significant reduction in expression of angiogenesis related factors such as PGF, VEGFC and VEGFR3 etc., which indicates pro-angiogenic role of YY1. (3) Silencing of YY1 also resulted in abrogation of hypoxic signaling pathway and reduction in MMP7 expression, which strongly indicates a putative role of YY1 in regulating metastasis and invasion of oral cancer cells. qRT-PCR validation results showed significant reduction in expression of both PGF and VEGFC upon inducible silencing of YY1. Similarly, expression of genes involved in EMT as well as metastasis such as VIM, TWIST and MMP7 were reduced upon silencing of YY1 in qRT-PCR experiment, indicating a regulatory role of $\mathrm{YY} 1 \mathrm{in}$ metastasis and invasion of oral cancer (Figure 5C). YY1 is known to positively regulate expression of cMyc, VEGF and Vimentin (VIM) genes through promoter activation from previous works of other groups [34-36]. Therefore, the findings of the present study are consistent with the previous reports and further corroborate the role of YY1 in modulating genes relevant in the context of cancer progression.

\section{Inducible silencing of YY1 impairs tumor growth in mice}

In order to understand the role of CARM1 and YY1 in tumor growth in vivo, xenograft studies were performed in NSG (NOD-SCID gamma) mice. AW8507_
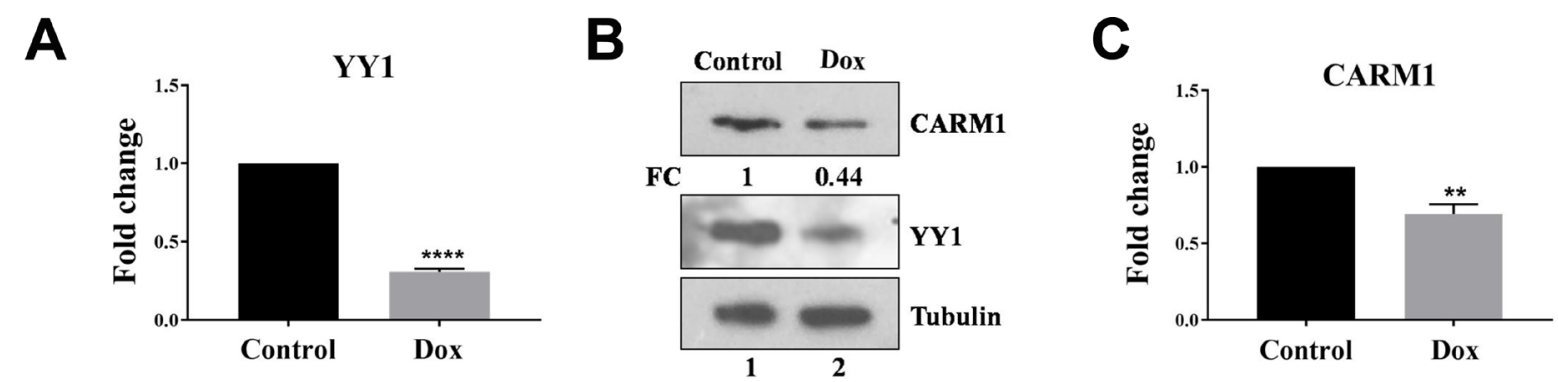

Dredicted YY1 binding sites on CARM1 promoter: 5'GGGACCTCTGGATCCCATGGTTGGATGGCTGGGGGGTGGA 3'

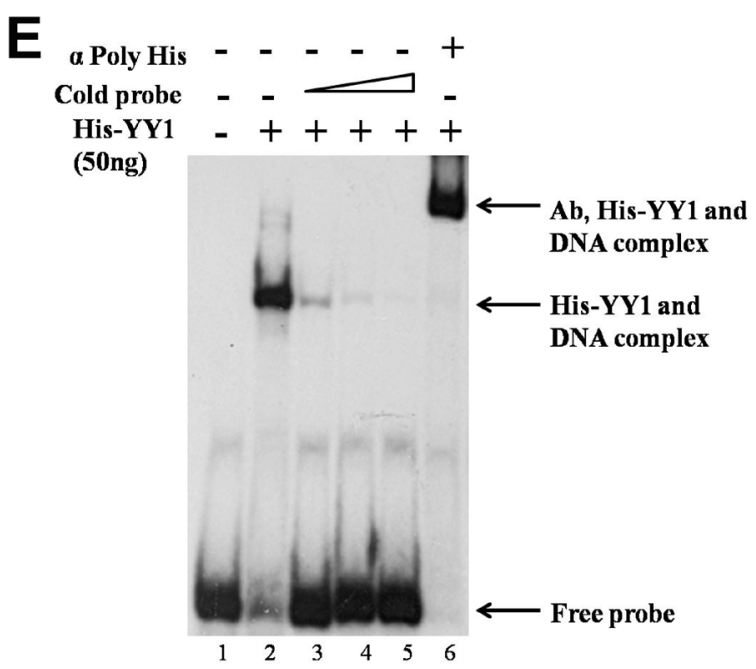

$\mathbf{F}$

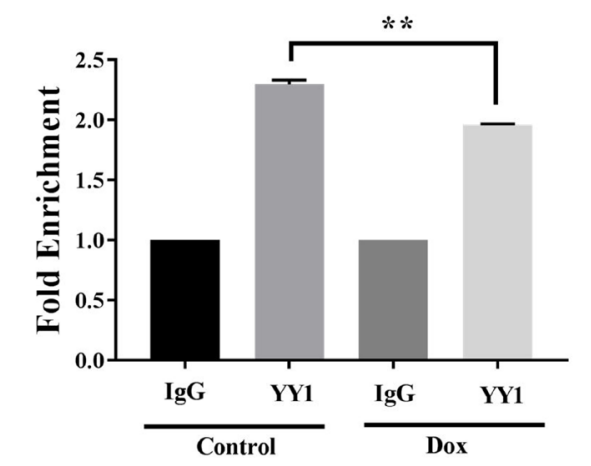

Figure 2: YY1 regulates CARM1 expression. (A) qRT-PCR to assess RNA expression of YY1 in AW8507_Tet-ON-shYY1 cells with Doxycycline treatment $\left(n=3,{ }^{* * *} p<0.001\right)$. (B) Immunoblotting to analyze protein expression of YY1 and CARM1 in AW8507_TetON-shYY1 cells with Doxycycline treatment (FC: Fold change). Data is representative of three independent experiments. (C) qRT-PCR to assess RNA expression of CARM1 in AW8507_Tet-ON-shYY1 cells with inducible silencing of YY1 $\left(n=3,{ }^{*} p<0.05\right)$. (D) The sequence of the probe taken from CARM1 promoter for EMSA. Putative YY1 binding sites have been highlighted. (E) EMSA with recombinant full length His-YY1 and radiolabelled oligonucleotide taken from CARM1 promoter. (F) ChIP to assess recruitment of YY1 on CARM1 promoter in AW8507_Tet-ON-shYY1 cells $\left(n=3,{ }^{* *} p<0.01\right.$, Dox: Doxycycline). 
Tet-ON-shYY1 cells showed a very prominent reduction in tumor growth upon inducible knock down of YY1 with Doxycycline treatment (Figure 6A, 6B). However, silencing of CARM1 did not result in as much change in tumor size as was seen with YY1 knock-down (Figure $6 \mathrm{C}, 6 \mathrm{D})$. In all cases, the body weight of mice remained unaffected by Doxycycline treatment throughout the experiment (Data not shown). The results of xenograft studies further corroborate the in vitro cellular data, emphasizing on the important role of YY1 in oral cancer growth.

\section{CARM1 methylates YY1 and coactivates YY1 mediated transcription}

Experimental evidences of the present study so far indicated a positive role of YY1 in regulation of CARM1 gene expression. Given the understanding that CARM1 is an arginine methyltransferase and known to methylate multiple transcription factors in cell, it was speculated that YY1 may also undergo arginine methylation. To test whether YY1 is a substrate of CARM1, in vitro methylation assays were performed with FLAG-CARM1 and His-YY1 in the presence of tritiated SAM and the samples were processed for autoradiography. CARM1 seemed to methylate full length YY1 in vitro (Figure 7A). Furthermore, immuno-pulldown experiment suggested in vivo interaction between FLAG-CARM1 and HA-YY1 in HEK293T cells (Figure 7B).

YY1 is known to interact with multiple coregulators in cell to modulate gene expression. For example, p300/ CBP and PRMT1 are known coactivators of YY1 mediated gene regulation $[37,38]$. Similarly, HDACs have been shown to function as corepressors for YY1 [39]. In the present study, to test the possibility of a role for CARM1 as a coactivator in the context of YY1 mediated gene regulation in cells, a reporter assay was performed using CARM1 promoter driven luciferase expression system. When CARM1 was exogenously overexpressed along with YY1 in HEK293T cells, the transactivation potential of YY1 was found to be enhanced, as indicated by increased luciferse activity (Figure 7C). The catalytically deficient mutant E267Q CARM1 showed similar activation of the luciferase reporter, indicating arginine methylation independent coactivator function of CARM1. This result also indicates a positive feedback loop for CARM1, where
A

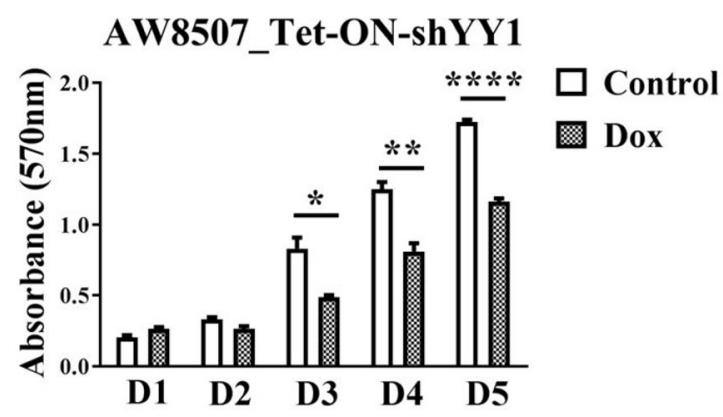

C

AW8507_Tet-ON-shYY1

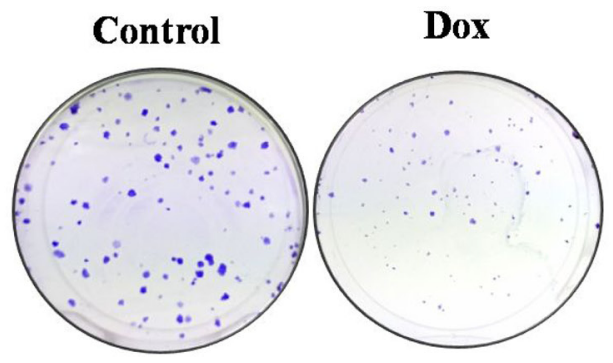

B

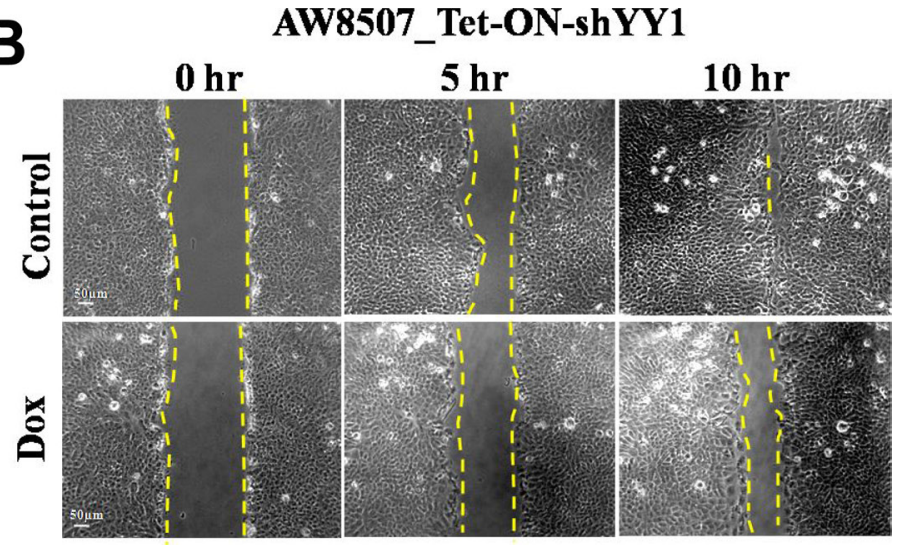

D

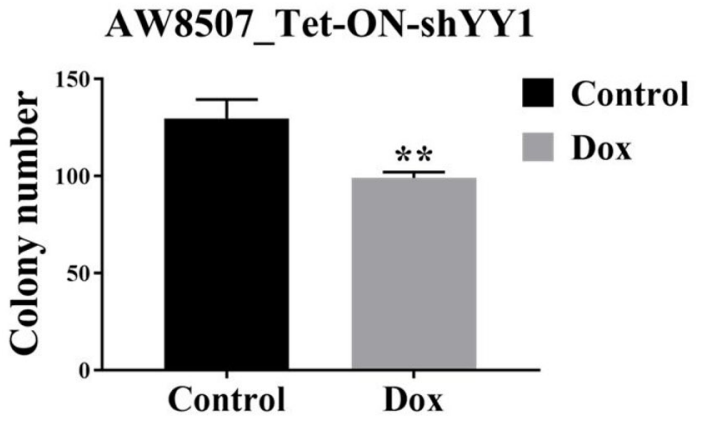

Figure 3: Elucidation of oncogenic role of YY1 in oral cancer cell line. (A) MTT assay with AW8507_Tet-ON-shYY1 cells with inducible silencing of YY1 expression $\left(n=3,{ }^{*} p<0.05,{ }^{* *} p<0.01,{ }^{* * * *} p<0.0001\right.$, D1-D5:Day1-Day5). (B) In vitro wound healing assay with AW8507_Tet-ON-shYY1 cells with inducible silencing of YY1 expression. Image scale: $50 \mu \mathrm{m}$. Data is representative of three independent experiments. (C) Clonogenic assay with AW8507_Tet-ON-shYY1 cells with inducible silencing of YY1 expression. (D) Quantitation of colony number $\left(n=3,{ }^{* *} p<0.01\right)$. 
CARM1 regulates its own gene promoter via coactivation of YY1.

Analysis on the amino acid sequence of YY1 revealed that the DNA binding domain of YY1 alone harbors 11 arginine residues, where the rest of protein harbors only 3 arginine residues. Thus, the probability of YY1-DBD being the putative target for methylation by CARM1 seemed to be high. To test this possibility, in vitro methylation assay was performed with DBD of YY1. Indeed, CARM1 was able to methylate the DNA binding domain of YY1 in vitro (Figure 7D). Methylation of YY1DBD by CARM1 was negatively affected in presence of a pharmacological inhibitor of CARM1 namely PRMT inhibitor V [40] (Figure 7E). In order to understand the effect of CARM1 in modulating DNA binding properties of YY1, EMSA was performed with YY1-DBD. CARM1 itself seemed to enhance DNA binding ability of YY1DBD in vitro, which did not seem to vary much when arginine methylation was allowed in presence of methyl donor SAM (Figure 7F). Therefore, CARM1 might enhance DNA binding properties of YY1 independent of arginine methylation of YY1.

Mass spectrometry analysis was performed to identify the sites of arginine methylation on YY1 mediated by CARM1. CARM1 seemed to methylate YY1-DBD on R281, R294, R323, R342, R363 and R381 in vitro. The A-Score, localization probability and the number of spectra providing evidence for each site have been listed
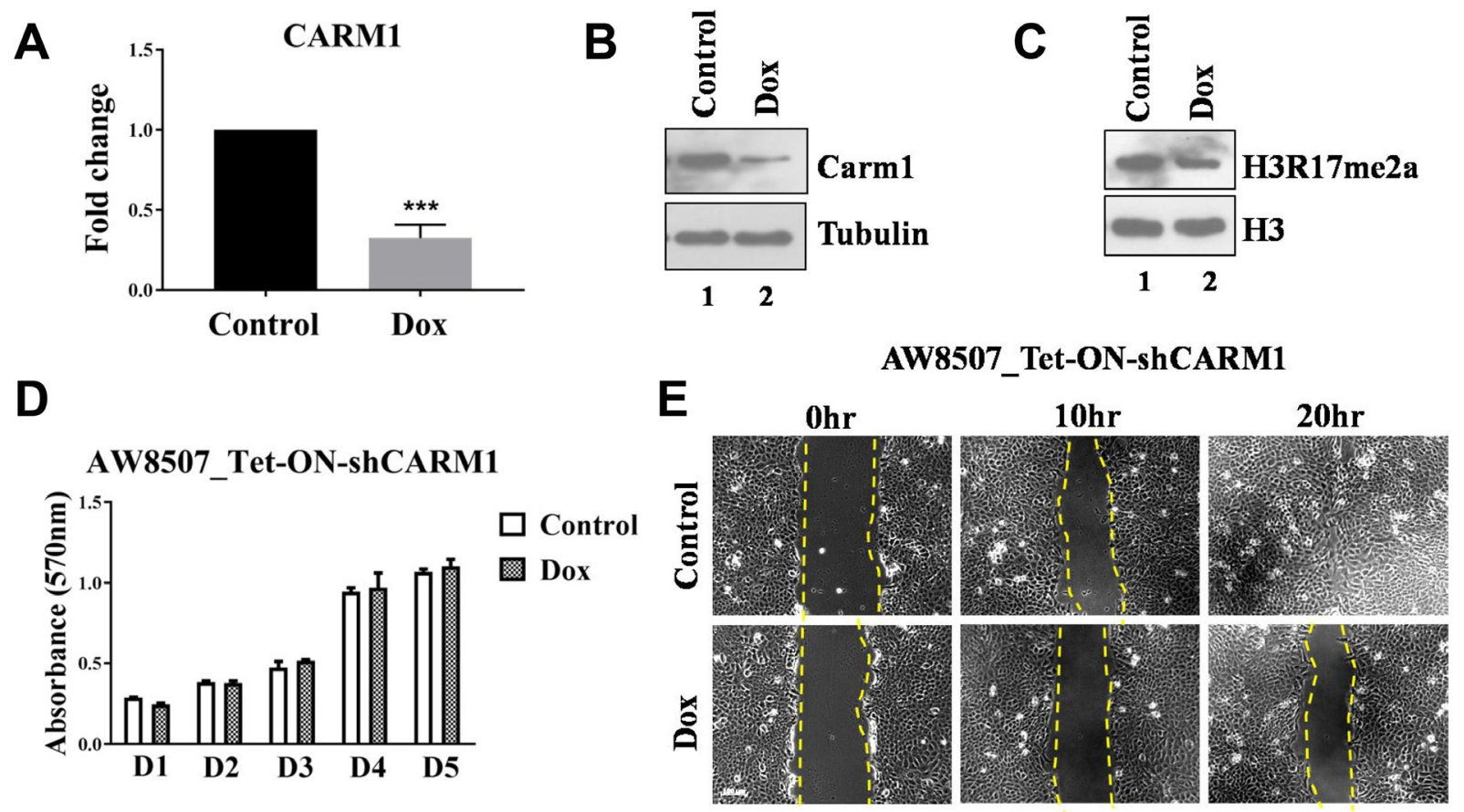

$\mathbf{F}$

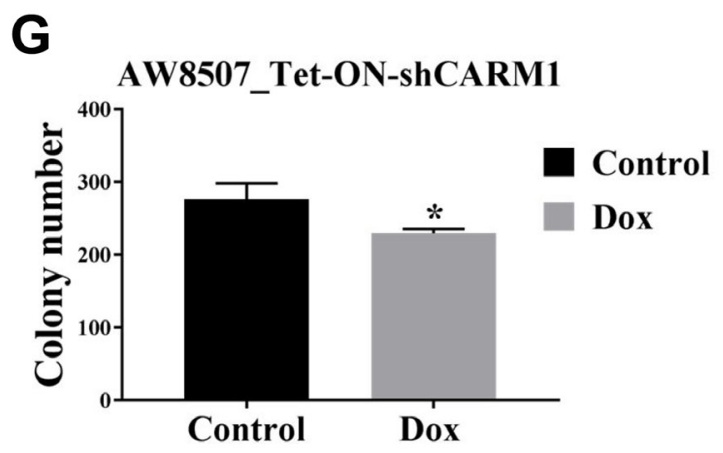

Figure 4: Elucidation of oncogenic role of CARM1 in oral cancer cell line. (A) qRT-PCR to assess RNA expression of CARM1 in AW8507_Tet-ON-shCARM1 cells with Doxycycline treatment $\left(n=3,{ }^{* * *} p<0.001\right)$. (B) Immunoblotting to assess protein expression of CARM1 in AW8507 Tet-ON-shCARM1 cells with Doxycycline treatment. Data is representative of three independent experiments. (C) Immunoblotting to assess levels of H3R17me2a upon inducible silencing of CARM1 expression in AW8507_Tet-ON-shCARM1 cells. Data is representative of three independent experiments. (D) MTT assay with AW8507_Tet-ON-shCARM1 cells with inducible silencing of CARM1 expression (D1-D5:Day1-Day5). (E) In vitro wound healing assay with AW8507_Tet-ON-shCARM1 cells with inducible knock-down of CARM1 expression. Image scale: $100 \mu \mathrm{m}$. Data is representative of three independent experiments. (F) Clonogenic assay with AW8507_Tet-ON-shCARM1 cells in presence of Doxyxycline. (G) Quantitation of colony number $\left(n=3,{ }^{*} p<0.05\right)$. 
A

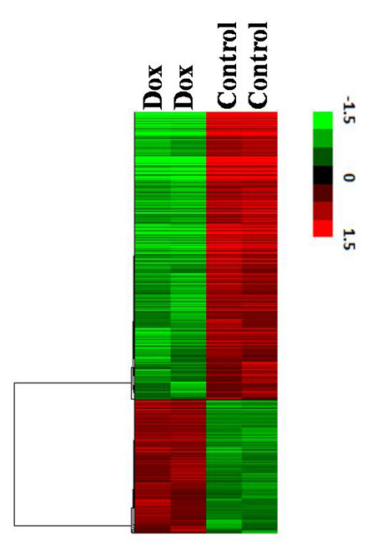

C AW8507 Tet-ON-shYY1

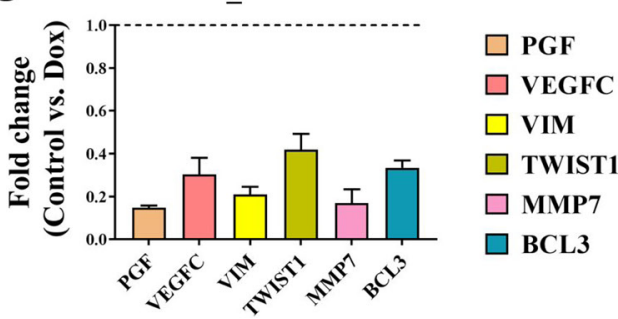

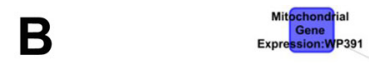

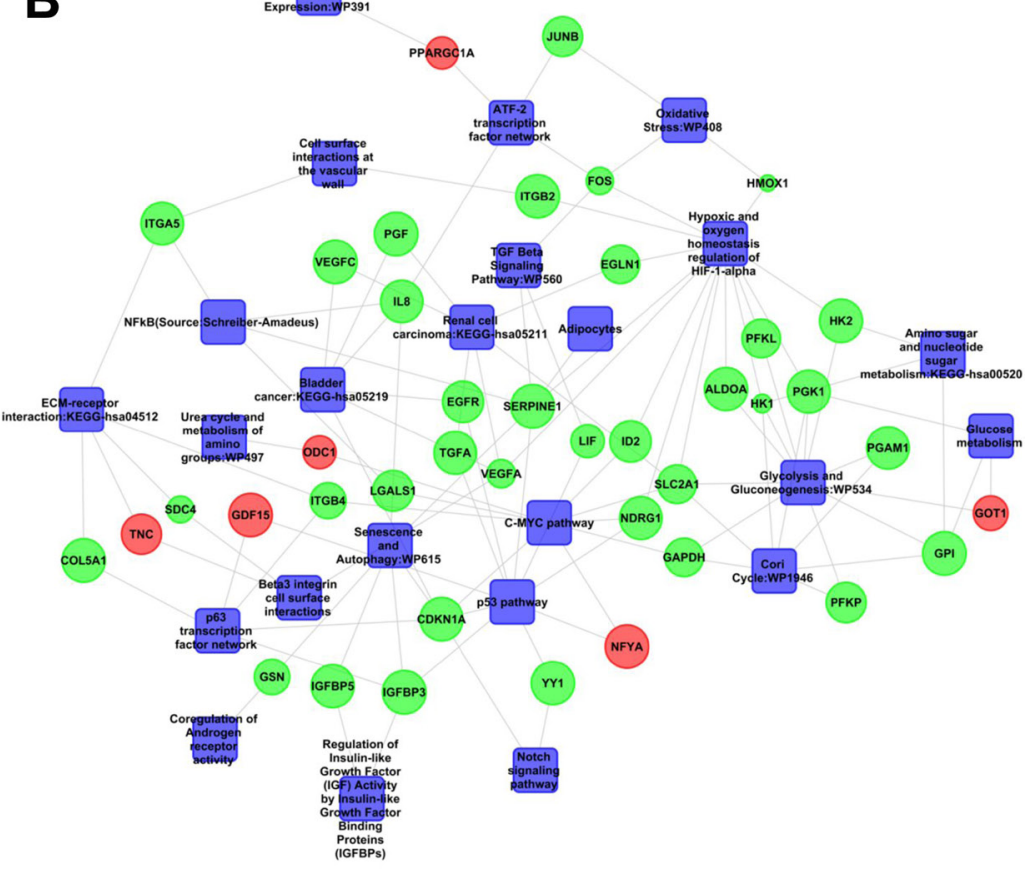

Figure 5: YY1 regulates multiple oncogenic pathways in oral cancer cells. (A) Array correlation heat map to show differential gene expression with a fold change value of 1.5 above the median expression value with hierarchical clustering from microarray performed in AW8507_Tet-ON-shYY1 cells. (B) A molecular network with integration of multiple pathways which were modulated upon inducible silencing of YY1. Green indicates downregulation, Red indicates upregulation. (C) qRT-PCR experiment to assess the expression of various genes related to cancer upon inducible silencing of YY1 in AW8507_Tet-ON-shYY1 cells $(n=3)$. Genes tested were PGF, VEGFC, VIM, TWIST1, MMP7 and BCL3.
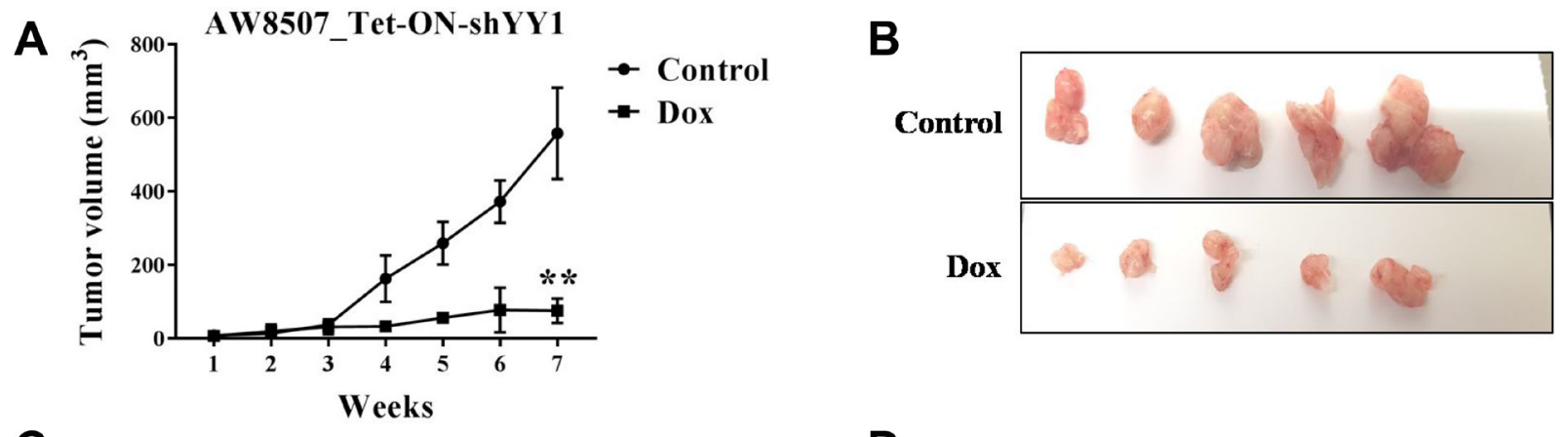

C

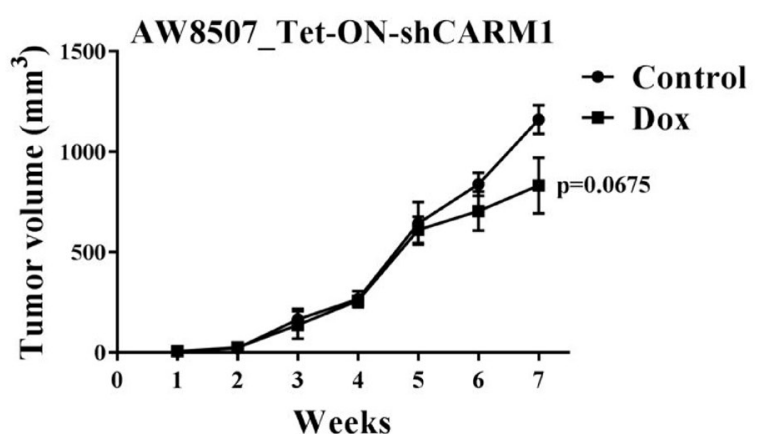

D

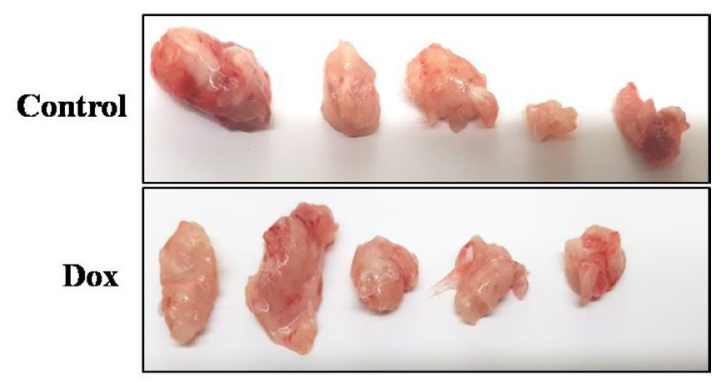

Figure 6: Xenograft study in nude mice with inducible silencing of YY1 and CARM1 in oral cancer cells. (A) Xenograft study with AW8507_Tet-ON-shYY1 cells $\left(n=5,{ }^{* *} p<0.01\right)$. (B) Images of dissected tumors of AW8507_Tet-ON-shYY1 cells after 7 weeks of growth. (C) Xenograft study with AW8507_Tet-ON-shCARM1 cells $(n=5, p=0.0675)$. (D) Images of dissected tumors of AW8507_Tet-ON-shCARM1 cells after 7 weeks of growth. 
in Table 1. Future studies will be necessary to determine relative propensity as well as in vivo relevance of above mentioned sites for arginine methylation mediated by CARM1.

\section{DISCUSSION}

CARM1 has been shown to be overexpressed in several cancer types such as colon cancer, prostate cancer and breast cancer [23-29]. In the present study CARM1 was also found to be upregulated in oral cancer patient tumor tissues. However, the mechanisms of transcriptional dysregulation in CARM1 expression in different pathophysiological conditions have not been addressed before. In this study we show that YY1 is a positive regulator CARM1 promoter. We also observed a positive correlation in protein expression of both YY1 and CARM1 in oral cancer tumor tissues. This observation indicates that YY1 mediated regulation of CARM1 gene promoter could be partly responsible for overexpression condition of CARM1 in oral cancer.

The roles of CARM1 and YY1 in the progression of oral carcinogenesis have not been explored before. In the present study investigation with silencing of both CARM1 and YY1 unraveled the oncogenic functions of both the proteins towards oral cancer manifestation. Inducible knock-down of CARM1 did not affect the proliferation ability of oral cancer cells; however it inhibited migration potential and colony formation by oral cancer cells. On the other hand, inducible silencing of YY1 resulted in reduced proliferation, reduced clonal propagation as well as slower migration of oral cancer cells. Transcriptomic analysis along with qRT-PCR validations suggested proproliferative, pro-angiogenic and pro-metastatic role of YY1. In this context, xenograft studies with silencing of YY1 clearly showed oncogenic role of YY1 in vivo.

YY1 was discovered to be a substrate of CARM1 mediated arginine methylation, where CARM1 could coactivate YY1 mediated reporter gene activation in cellulo. It would be necessary to characterize the sites of arginine methylation on YY1 that were identified from mass spectrometry. Although CARM1 could coactivate YY1 mediated transcription independent of its methyltransferase activity, study on the sites of arginine methylation would provide biochemical insight to understand the effect of the modification on molecular properties of YY1 as well as to understand different probable cross-talks with other posttranslational modifications.
A

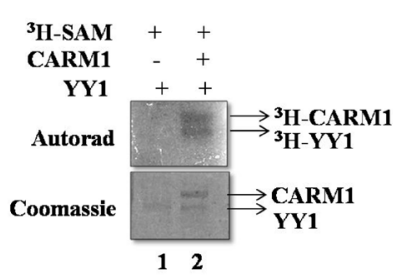

D

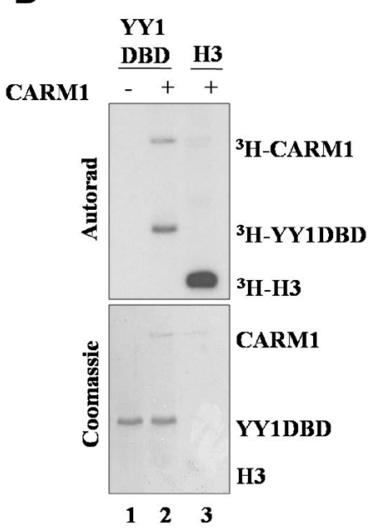

B

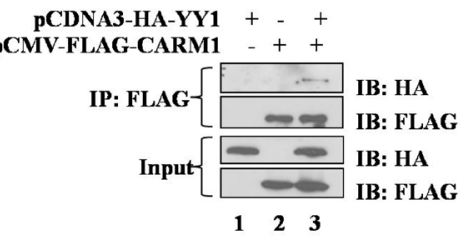

E

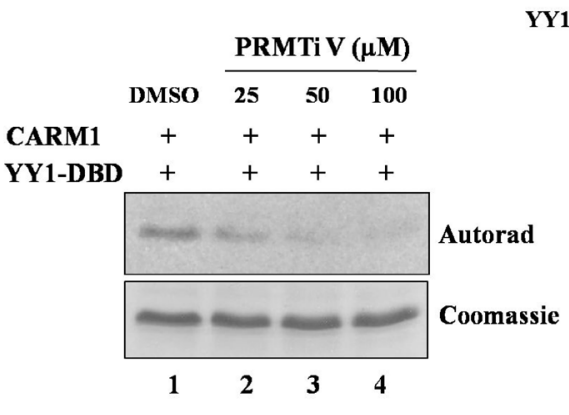

$\mathbf{F}$
C
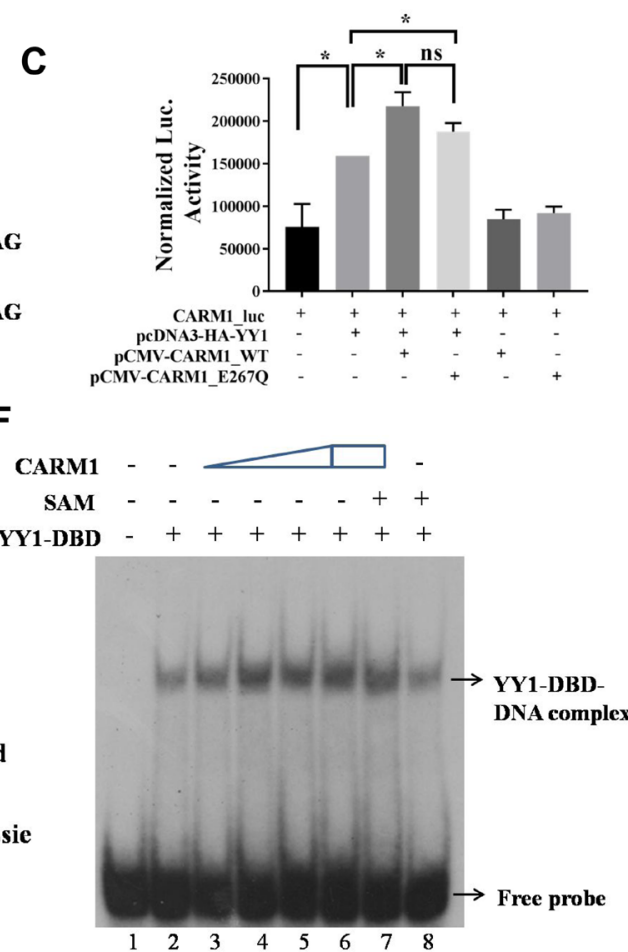

Figure 7: CARM1 methylates YY1. (A) In vitro methylation assay with recombinant full length His-YY1 and FLAG-CARM1 in presence of tritiated SAM. (B) Immuno-pull down assay to assess in vivo interaction between YY1 and CARM1 (IP: Immunopulldown and IB: Immunoblotting). (C) Reporter luciferase assay to assess coactivation potential of CARM1 in the context of YY1 driven gene expression $\left(n=2,{ }^{*} p<0.05\right)$. (D) In vitro methylation assay with recombinant His-YY1-DBD and FLAG-CARM1 in presence of tritiated SAM. (E) In vitro methylation assay with His-YY1-DBD and FLAG-CARM1 in presence of tritiated SAM and PRMT inhibitor V (25, 50 and $100 \mu \mathrm{M}$ ). (F) EMSA to determine effect of arginine methylation on DNA binding ability of YY1-DBD (15 minutes methylation assay +15 minutes DNA binding assay). 
Table 1: The list of arginine residues on YY1 found to be methylated by mass spectrometry

\begin{tabular}{llcccc}
\hline S.N. & Sites & Modification & Best A score & Localization probability & SpC \\
\hline 1 & R281 & Methyl & 169.11 & 1.000 & 3 \\
2 & R294 & Methyl & 211.02 & 1.000 & 3 \\
3 & R323 & Methyl & 188.24 & 1.000 & 11 \\
4 & R342 & Methyl & 46.21 & 1.000 & 1 \\
5 & R363 & Methyl & 168.56 & 1.000 & 1 \\
6 & R381 & Methyl & 1000.0 & 1.000 & 9 \\
7 & R381 & Dimethyl & 26.34 & 0.995 & 1 \\
\hline
\end{tabular}

Methylation status, best A-Score, localization probability and the number of spectra providing evidence for each site have been indicated.

Transcriptomic analysis with knock down of CARM1 in the context of oral cancer would be necessary to identify the genes which are regulated by both YY1 and CARM1. This would help us to distinguish the set of YY1 responsive genes which are CARM1 dependent in the context of oral cancer. It would be interesting to investigate whether YY1 employs CARM1 to regulate expression of both oncogenes as well as tumor suppressor genes in context dependent manner. As CARM1 has not been reported to possess corepressor activity, tumor suppressive YY1 might also utilize coactivator properties of CARM1 to activate tumor suppressor genes to inhibit tumor growth in certain cancer types (Figure 8).

Apart from assisting YY1 in regulating gene expression, CARM1 overexpression also implies that there would be increased availability of CARM1 for other cellular functions which may have significant implications in oral carcinogenesis that are independent of YY1 function. It could be via coactivation of transcription factors other than YY1, through chromatin remodeling function of CARM1 or even via modulation of RNA metabolism in cell. CARM1 is the only PRMT family member responsible for deposition of H3R17me2a modification on chromatin, which is known to favor transcriptional activation [41]. In the present study immunohistochemistry analysis reveals higher prevalence of H3R17me2a mark in oral cancer patient samples; a promising observation which might indicate the possibility of H3R 17 me 2 a modification to be considered as a diagnostic epigenetic mark in oral cancer in near future. Clinically relevant RNAi therapy and small molecule inhibitors could also be developed and employed targeting YY1 and CARM1 to suppress oral cancer growth in near future.

\section{MATERIALS AND METHODS}

\section{Patient tumor samples}

Oral cancer patient tumor tissues were obtained from HCG-BIO, Sri Devaraj Urs Medical college, Kolar, Bangalore and NEHU, Shillong, India. The clinico- pathological information available on the oral cancer patients have been summarized in Supplementary Table 1. The patients were of both the genders: males $(60 \%)$ and females (40\%) aged between $28-87$ yrs. Out of 30 tumor samples, $22(73.33 \%)$ were of grade I, $6(20 \%)$ were of grade II and 2 $(6.67 \%)$ were of grade III in cellular differentiation.

\section{Immunohistochemistry analysis}

Tumor and adjacent normal tissues from oral cancer patients were collected in formalin from hospital on the day of surgery. The tissues were dehydrated, paraffin embedded, and sectioned with a microtome (Leica). The sectioned tissues were baked on glass slides at higher temperature followed by deparaffinization in xylene. The tissue sections were rehydrated with sequential immersion in graded alcohols $(100 \%, 70 \%, 50 \%$ in PBS $)$. The antigen retrieval was done by treating the rehydrated sections with low $\mathrm{pH}$ citrate buffer. Then peroxidase block with $3 \%$ $\mathrm{H}_{2} \mathrm{O}_{2}$ followed by blocking with $5 \%$ skimmed milk was carried out. The sections were incubated with different primary antibodies and then secondary antibodies in 1\% skimmed milk. Tissue sections were incubated with StreptAvidin Biotin kit (Dako) reagents. Immuno-reactivity (brown precipitate) was allowed to develop in the presence of DAB (Diaminobenzidine tetrahydrochloride) (Sigma), and counterstaining was done with Hematoxylin. The stained tissues were mounted with a cover slip with the help of DPX. The images of immune-stained tissues were taken with the help of microscope and H-scoring was performed. The oral cells were counted and based on the intensity of staining, scores were calculated as follows: 1 $\times$ percentage of weakly stained nuclei $+2 \times$ percentage of moderately stained nuclei $+3 \times$ percentage of strongly stained nuclei giving a range of 0 to 300 of $\mathrm{H}$-score.

\section{Cell culture}

HEK293T cell line was obtained from ATCC (American Type Culture Collection). AW8507 cell line (RRID: CVCL_D653, [45]) was obtained from ACTREC, 
Mumbai, India. Both HEK293T and AW8507 cell lines were grown in DMEM (Dulbecco's Modified Eagle's Medium). AW8507 cells containing Tet-ON-shYY1 and Tet-ON-shCARM1 (post transfection with respective plasmids) isolated with Puromycin selection and FACS for RFP positivity. In all cases the growth medium was supplemented with 10\% FBS (Fetal Bovine Serum) for cell culture irrespective of the cell line. All the mammalian cell lines were grown in $37^{\circ} \mathrm{C}$ incubator with $5 \% \mathrm{CO}_{2}$ and $90 \%$ relative humidity.

Luciferase assay with CARM1 promoter, Immunoblotting, total RNA isolation, qRT-PCR and ChIPqPCR: Performed as described in Behera AK et al., (2018) $F E B S J$. (The nucleotide sequences of primers used in the study have been listed in Supplementary Table 3).

\section{Purification of FLAG-CARM1 from Sf21 cells}

Sf21 cells were grown in TC100 medium in $25^{\circ} \mathrm{C}$ incubator. 6-7 million cells were seeded in each of 10 , $150 \mathrm{~mm}$ dishes and infected with baculovirus containing CARM1 expression plasmid for 64-70 hrs. The infected cells were scraped off the plates to collect in PBS and harvested by centrifugation at $2000 \mathrm{rpm}$ at $4^{\circ} \mathrm{C}$. Cells were once washed with PBS followed by resuspension in lysis buffer (20 mM Tris-Cl, pH 7.4, $500 \mathrm{mM} \mathrm{NaCl}$, $4 \mathrm{mM} \mathrm{MgCl}, 2 \mathrm{mM}$ EDTA, $2 \mathrm{mM}$ DTT, $20 \mathrm{mM}$ $\beta$-glycerophosphate, $0.4 \mathrm{mM}$ PMSF, $20 \%$ glycerol). Dounce homogenizer was used for effective lysis of cells (4 strokes, 6 times in $3 \mathrm{~min}$ intervals on ice). The sample post homogenization was diluted with dilution buffer (20

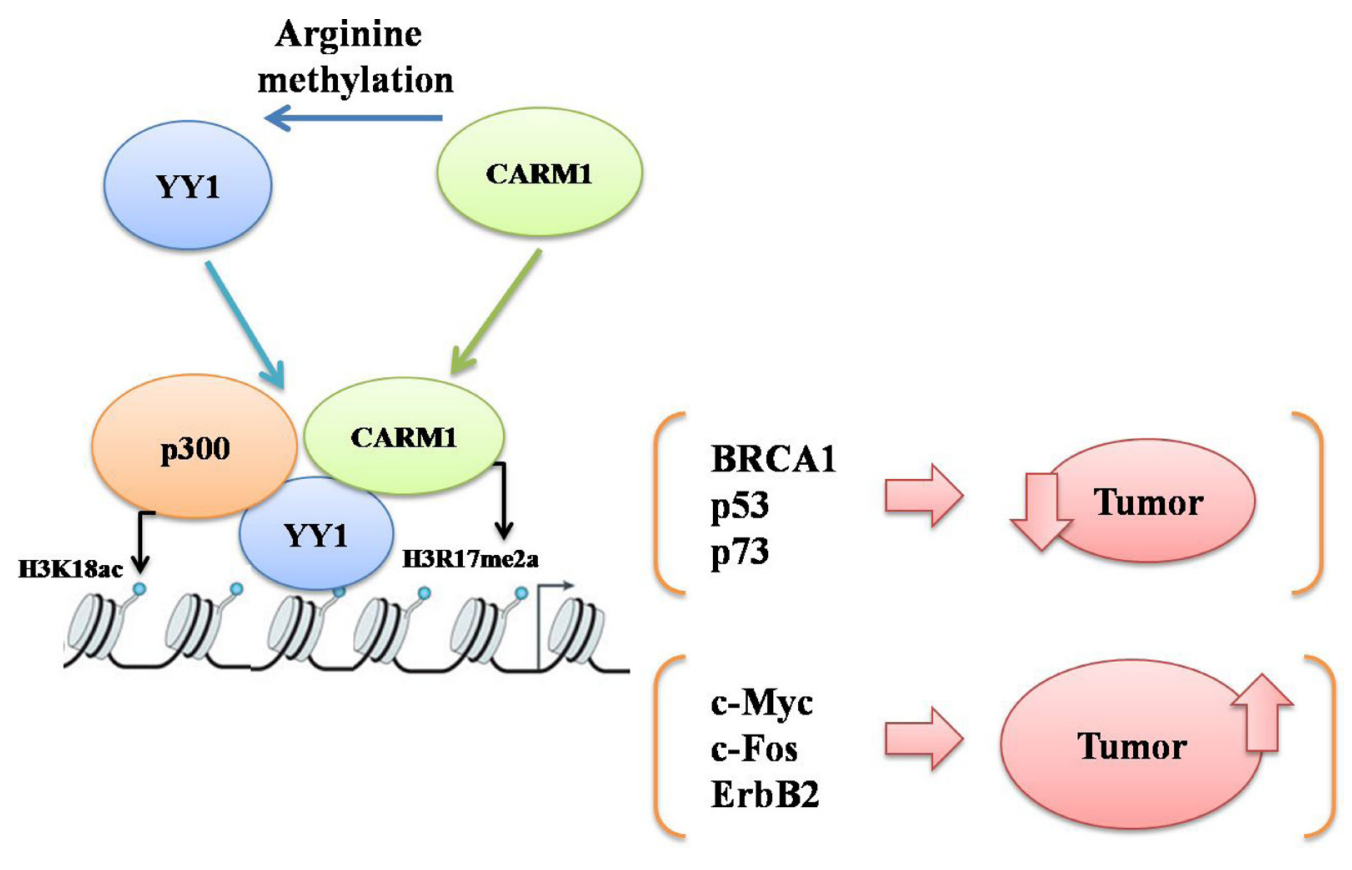

mM Tris-Cl, pH 7.4, 10\% glycerol, $0.02 \%$ NP-40). The lysed cells were centrifuged at $16000 \mathrm{rpm}$ for $30 \mathrm{~min}$ at $4^{\circ} \mathrm{C}$ and the resultant supernatant was incubated with M2 agarose beads for $3 \mathrm{hrs}$ at $4^{\circ} \mathrm{C}$ on end to end rotor. The beads were washed with wash buffer $(20 \mathrm{mM}$ Tris- $\mathrm{Cl} \mathrm{pH}$ 7.4, $150 \mathrm{mM} \mathrm{NaCl}, 2 \mathrm{mM} \mathrm{MgCl}{ }_{2}, 0.2 \mathrm{mM}$ EDTA, $1 \mathrm{mM}$ DTT, $10 \mathrm{mM} \beta$-glycerophosphate, $0.2 \mathrm{mM}$ PMSF, $0.01 \%$ NP40, 15\% glycerol) for 4-5 times followed by elution of bound protein with elution buffer (BC100 with $150 \mathrm{ug} / \mathrm{ml}$ FLAG peptide) at $4^{\circ} \mathrm{C}$.

\section{Purification of His-YY1 from $E$. coli}

E. coli BL21 cells transformed with bacterial expression vector of pET28b-His-YY1, were grown in LB medium and induced with $1 \mathrm{mM}$ IPTG at cell density $\mathrm{OD}_{600}$ of 0.6 . Induced cells were grown in $37^{\circ} \mathrm{C}$ for $3 \mathrm{hrs}$, then pelleted, resuspended in Buffer A $(6 \mathrm{M}$ Guanidine $\mathrm{HCl}, 25 \mathrm{mM}$ Tris-Cl, $\mathrm{pH} 8.0,100 \mathrm{mM}$ $\mathrm{NaCl}, 5 \mathrm{mM} \beta \mathrm{ME}, 10 \mathrm{mM}$ Imidazole) and sonicated. Centrifugation of the lysed cells was done at 16,000 rpm for 30 minutes at $4^{\circ} \mathrm{C}$. Supernatant was incubated with Ni-NTA beads for $3 \mathrm{hrs}$ at $4^{\circ} \mathrm{C}$ with constant rotation. Beads were washed with Buffer A with $30 \mathrm{mM}$ imidazole for 5-6 times. Elution was done with Buffer A containing $400 \mathrm{mM}$ Imidazole. Eluted proteins were pulled together and dialyzed against Refolding buffer (25 mM Tris-Cl/50 mM HEPES pH 7.8, $10 \mathrm{mM} \mathrm{MgCl}_{2}$, $100 \mathrm{mM} \mathrm{NaCl}, 5 \mathrm{mM}$ DTT and $0.1 \mathrm{mM} \mathrm{ZnCl}_{2}$ ). The dialysate was centrifuged and supernatant containing purified His-YY1 was stored.

Figure 8: A schematic to explain probable mechanisms of cooperative action between YY1 and CARM1 either to suppress or promote carcinogenesis by upregulating either YY1 responsive tumor suppressor genes (such as BRCA1, p53 and p73) or YY1 responsive oncogenes (such as c-Myc, c-Fos and Erb B2) respectively in a context dependent manner. 


\section{Purification of His-YY1-DBD (aa 223-414) from E. coli}

E. coli BL21 cells harboring pET28b-His-YY1DBD expression plasmid were grown in $100 \mathrm{ml}$ of LB medium at $37^{\circ} \mathrm{C}$ for overnight, which was scaled up to $1 \mathrm{~L}$ the next day. The optical density of bacterial culture was measured at repeated intervals at $600 \mathrm{~nm}$ of wave length and when absorbance value reached 0.6 , bacterial cells were induced with $0.5 \mathrm{mM}$ IPTG for $3 \mathrm{hrs}$ at $37^{\circ} \mathrm{C}$. The bacterial culture was centrifuged to harvest the cells. The bacterial cells were resuspended in lysis buffer $(20 \mathrm{mM}$ Tris-Cl, pH 7.5, 20\% glycerol, $0.2 \mathrm{mM}$ EDTA, $0.3 \mathrm{M} \mathrm{KCl}$, $0.1 \%$ NP40, $20 \mathrm{mM}$ Imidazole, $2 \mathrm{mM}$ PMSF, and $2 \mathrm{mM}$ $\beta$-ME) and sonicated in order to lyse the cells. The lysed cells in buffer were centrifuged at $16000 \mathrm{rpm}$ for $30 \mathrm{mins}$ at $4^{\circ} \mathrm{C}$. The resulting supernatant was incubated with $\mathrm{Ni}$ NTA beads for $3 \mathrm{hrs}$ at $4^{\circ} \mathrm{C}$ on end to end rotor. The beads were washed once with lysis buffer and 4-5 times with wash buffer (20 mM Tris-Cl, pH 7.5, 20\% glycerol, 0.2 mM EDTA, 0.3M KCl, 0.1\% NP40, 40 mM Imidazole, 2 $\mathrm{mM}$ PMSF and $2 \mathrm{mM} \beta$-ME). The protein bound to beads were eluted with elution buffer ( $20 \mathrm{mM}$ Tris-Cl, $\mathrm{pH} 7.5$, $20 \%$ glycerol, $0.1 \mathrm{mM}$ EDTA, $2 \mathrm{mM}$ PMSF, $0.5 \mathrm{M} \mathrm{KCl}$, $0.2 \% \mathrm{NP} 40,300 \mathrm{mM}$ imidazole and $1 \mathrm{mM} \beta-\mathrm{ME})$ at $4^{\circ} \mathrm{C}$.

\section{In vitro methylation assay}

Recombinant full length enzyme FLAGCARM1 and recombinant substrates were incubated in methyltransferase buffer $(20 \mathrm{mM}$ Tris- $\mathrm{HCl}, \mathrm{pH}$ 8.0, 4 mM EDTA, $200 \mathrm{mM} \mathrm{NaCl}$ ) with S-adenosyl-L-[methyl$\left.{ }^{3} \mathrm{H}\right]$ methionine (15 Ci/mmol, NEN-Perkin Elmer) or unlabelled SAM according to the necessity of the experiment, at $30^{\circ} \mathrm{C}$ for desired period of time. Reaction mixture was run on $12 \%$ SDS PAGE. Gel was Coomassie stained and destained and processed for autoradiography.

\section{Electrophoretic mobility shift assay}

Target DNA oligonucleotides from CARM1 promoter (Listed in Supplementary Table 3) were end labelled with $\gamma^{32} \mathrm{P}$ ATP using T4 Polynucleotide kinase and isolated via Phenol-chloroform-isopropanol (PCI) extraction method. The aqueous phase obtained from PCI separation was incubated with absolute ethanol in presence of sodium acetate and stored in $-80^{\circ} \mathrm{C}$ for $1 \mathrm{hr}$. The labeled oligonucleotides were obtained in the form of a pellet upon centrifugation at $16000 \mathrm{rpm}$. The labeled single strand DNA pellet was air dried and reconstituted in annealing buffer (10 mM Tris-Cl, $\mathrm{pH} 8.0,20 \mathrm{mM} \mathrm{NaCl})$ with addition of equimolar amounts of complementary strand. The annealing was allowed to occur at $85^{\circ} \mathrm{C}$ with gradual cooling to RT. The annealed double strand probes were purified by passing through Sephadex C-50 column. The activity of radiolabelled probes was measured with the help of scintillation counter. Labelled oligonucleotides with $5000 \mathrm{cpm}$ were incubated with respective recombinant proteins at $30^{\circ} \mathrm{C}$ for 30 minutes in EMSA buffer $(10 \%$ glycerol, $75 \mathrm{mM} \mathrm{KCl}, 10 \mathrm{mM}$ HEPES, $5 \mathrm{mM} \mathrm{MgCl}_{2}$ ) and complexes were resolved on $5 \%$ native PAGE (5\% acrylamide: bisacrylamide (19:1) mix, $0.5 \mathrm{X}$ TBE, $0.1 \%$ APS, $0.03 \%$ TEMED) for $2 \mathrm{hrs}$ at $4^{\circ} \mathrm{C}$. Gel was dried and kept for exposure to X-ray films.

\section{Immuno-pulldown assay}

HEK293T cells were transfected with pcDNA3HA-YY1 and pCMV-FLAG-CARM1 plasmids. After $24 \mathrm{~h}$, adherent cells were lysed with lysis buffer (50 $\mathrm{mM}$ Tris-Cl, pH 7.4, $150 \mathrm{mM} \mathrm{NaCl}, 1 \mathrm{mM}$ EDTA, 1\% Triton-X 100) on a rocker at $4^{\circ} \mathrm{C}$ for 30 minutes. Samples were collected in centrifuge tubes and kept on ice for 15 minutes and then subjected to centrifugation at 2000rpm for 15 minutes at $4^{\circ} \mathrm{C}$. Supernatant was incubated with M2 agarose beads (equilibrated with lysis buffer) for 6 $\mathrm{h}$ at $4^{\circ} \mathrm{C}$ on a rotating rocker. Beads were collected with centrifugation at $2000 \mathrm{rpm}$ for 10 minutes at $4^{\circ} \mathrm{C}$. Beads were washed with lysis buffer (once) and wash buffer (20 $\mathrm{mM}$ Tris-Cl, pH 7.4, $150 \mathrm{mM} \mathrm{NaCl}, 2 \mathrm{mM} \mathrm{MgCl} 2,1 \mathrm{mM}$ DTT, 0.2 mM EDTA, 0.01\% NP-40, 0.2 mM PMSF, 10 $\mathrm{mM} \beta$-Glycerophosphate, $15 \%$ Glycerol) several times. Elution was performed with BC100 containing $200 \mathrm{ng} /$ ul of FLAG peptide. Immunoblotting was performed with HA and FLAG tag-specific antibodies.

\section{MTT assay}

Cells were seeded in 96 well plates and maintained under desired conditions. On the respective days cells were treated with MTT [3-(4,5-dimethylthiazol-2-yl)-2,5diphenyltetrazolium bromide] at the final concentration of $0.5 \mathrm{mg} / \mathrm{ml}$ in growing media for $2 \mathrm{hrs}$ to allow intracellular reduction of above mentioned tetrazolium dye (yellow) to insoluble formazan (purple) by oxidoreductase enzymes. Then the media was aspirated and the cells were added with DMSO (Dimethyl Sulfoxide) as the solubilization agent for formazan. After 15 minutes, the colored solution (solubilized formazan in DMSO) was saved and taken for colorimetric quantification. Absorbance was measured at OD of $570 \mathrm{~nm}$ with the help of a multiwell scanning spectrophotometer (ELISA reader). The degree of light absorption (absorbance values) were plotted to correlate with cellular number as indirect representation of cellular proliferation.

\section{Clonogenic assay}

The cells were seeded in 6 well plates $(\sim 500$ per well) with desired conditions in triplicates and allowed to grow for 10 days. The colonies of cells thus produced, were fixed with ice cold methanol for 25 minutes followed by staining with $0.5 \%$ crystal violet solution prepared in methanol, for $2 \mathrm{hrs}$. The colonies of cells were washed 
with PBS, dried and then processed for imaging as well as estimation of colony number.

\section{In vitro wound healing assay}

Cells were seeded in $30 \mathrm{~mm}$ dishes and grown to confluency. A straight scratch was produced on the monolayer of cells with the help of a microtip. Then live cell imaging of cells was performed with the microscope (Axiovert 200M) focused on the scratch for $24 \mathrm{hrs}$, where images were taken at intervals of 5 minutes to monitor closure of scratch as a reflection of cellular migration.

\section{Xenograft study}

All procedures involving animals were reviewed and approved by the NUS Institutional Animal Care and Use Committee. NOD-SCID gamma (NSG) mice (7 week old) were purchased from InVivosPte Ltd. (Singapore). The mice were implanted with either AW8507 Tet-ONshYY1 or AW8507_Tet-ON-shCARM1 $\left(1 \times \overline{1} 0^{6}\right.$ cells $)$ mixed with $10 \%$ matrigel matrix (BD Biosciences, USA) subcutaneously on the flank region. Doxycycline hyclate treatment was started when the size of the tumor was 0.2 to $0.3 \mathrm{~cm}$. The mice were given either plain water (vehicle control) or doxycycline $(200 \mu \mathrm{g} / \mathrm{ml})$ and $1 \%$ sucrose mixed in drinking water for seven weeks. The tumor size and body weight of the mice was measured once a week for the duration of the experiment. The tumor volume was calculated using the formula $\left[\mathrm{L} \times \mathrm{W}^{2}\right] / 2$, where $\mathrm{W}$ and $\mathrm{L}$ are the width (short diameter) and the length (long diameter) of the tumor respectively.

\section{Reagents, plasmids and antibodies}

TC100 insect medium (Ref: IML007), PBS (Ref: TL1006), Trypsin-EDTA solution 10× (Ref: TCL070) and Antibiotic antimyotic solution 100× (Ref: A002A) were obtained from HIMEDIA. The lipofectamine used for transfection was obtained from Invitrogen (Ref: 11668019). DMEM powder (Ref: D1152), MTT (Ref: M5655) and SAM (Ref: A7007) were obtained from Sigma-Aldrich (St. Louis, Missouri, USA). TRIzol reagent (Ref: 15596018) was obtained from ambion life technologies. The TRIPZ-shRNA plasmids used for stable cell line generation were obtained from Dharmacon (Ref: CARM1 sh -V3THS_319980 and YY1 sh-V2THS_219592). The commercial antibodies used in the study include Tubulin from calbiochem (Ref: CP06), CARM1 from abcam (Ref: Ab84370), YY1 from abcam (Ref: Ab12132) and H3R17me2a from Millipore (07-214). Tritiated SAM was obtained from PerkinElmer (Ref: NET155250UC). Luciferase assay buffer (Ref: E151A) and reporter lysis buffer (Ref: E397A) were purchased from Promega (Madison, Wisconsin, USA). CARM1 inhibitor (PRMT inhibitor V) was purchased from Calbiochem-Millipore (Ref: 217531).

\section{Transcriptomic analysis by microarray}

Total RNA was isolated from cells grown under different assay conditions. The quality and quantity of RNA was assessed spectrophotometrically by a Nanodrop and Bioanalyzer. Equal amounts of RNA samples were used to prepare cDNA library and processed for transcriptomic analysis using Illumina Gene Expression arrays. The raw data obtained from hybridization to illumina HT-12 array, was quantile normalized followed by baseline transformation to median of all the samples using GeneSpring GX 12.5 software. The differentially expressed genes were identified across the samples using volcano plot with a fold change threshold of 1.5 and $t$ test $p$ value threshold adjusted for false discovery rate less than 0.001 for statistical significance. Hierarchical clustering of differentially expressed genes in treated vs. control conditions was done using Euclidian algorithm with Centroid linkage rule to identify gene clusters whose expression levels were significantly reproduced across the replicates. Differentially expressed genes were subjected to biological significance analysis by GOElite tool to determine enriched biological pathways. Over representation Analysis (ORA) of significant biological categories (GeneOntology and Pathway) involving differentially expressed transcripts was performed and a network was modeled. GEO accession number for the microarray data: GSE125317.

\section{Mass spectrometry analysis}

In vitro methylated His-YY1-DBD by FLAGCARM1 in presence of SAM was separated on $12 \%$ SDS-PAGE. The destained gel bands containing the methylated targeted protein were washed with 25 $\mathrm{mM}$ ammonium bicarbonate followed by acetonitrile. Proteins were reduced with $10 \mathrm{mM}$ dithiothreitol at $60^{\circ} \mathrm{C}$ followed by alkylation with $50 \mathrm{mM}$ iodoacetamide at RT. Proteins were subjected to multi-enzyme digestion as follows: trypsin (Promega) for $4 \mathrm{~h}$, chymotrypsin/elastase (Promega) for $12 \mathrm{~h}$ at $37^{\circ} \mathrm{C}$ followed by Quenching with formic acid. Each gel digest was analyzed by nano LC/MS/MS with a Waters NanoAcquity HPLC system interfaced to a ThermoFisher Q Exactive at MS Bioworks, LLC (Ann Arbor, MI). Peptides were eluted through a $75 \mu \mathrm{m}$ analytical column of Luna C18 resin (Phenomenex) at $350 \mathrm{~nL} / \mathrm{min}$. The mass spectrometer was operated in data-dependent mode. MS and MS/MS were performed in the Orbitrap at 70,000 FWHM and 17,500 FWHM resolutions respectively. The fifteen most abundant ions were selected for MS/MS. Byonic mzID files were parsed into Scaffold software to validate and filter and to create a nonredundant list per sample. Data were filtered using a minimum peptide value of $50 \%$ (Prophet scores) and a minimum protein value of $95 \%$ requiring at least two unique peptides per protein. 


\section{Bioinformatic analysis with TCGA RNA-seq data}

RSEM normalized expression data pertaining to CARM1 and YY1 was downloaded from www.cbioportal. org. The TCGA RNA-Seq data corresponding to 32 different tumor types was plotted as a box-whisker plot using R software [42]. To further interpret the expression status of the two genes, PCA analysis using two different $\mathrm{R}$ packages [43, 44] was carried out to study the correlation between the expression patterns of the genes across different cancers.

\section{Statistical analysis}

All the statistical analyses were performed using GraphPad Prism 7 Software (California, USA). The data obtained from three independent experiments were expressed as mean \pm SEM. Two tailed unpaired Student's $t$-test was used to determine the statistical significance values. A $p$-value of equal to or less than 0.05 was considered statistically significant.

\section{Abbreviations}

BCl2: B-cell lymphoma 2; BRCA1: Breast cancer 1; CARM1: Coactivator associated arginine methyltransferase; DR: Death Receptor; ESCC: Esophageal squamous cell carcinoma; MMP: Matrix metalloproteinase; MEF2C: Myocyte enhancer factor2C; OSCC: Oral squamous cell carcinoma; PRMT: PGL: Placental growth factor, Protein arginine methyltransferase; SAM: S-adenosyl- L-methionine; TGF: Transforming growth factor; TNF- $\alpha$ : Tumor necrosis factor alpha; TRAIL: TNF-related apoptosis-inducing ligand; VEGFC: Vascular Endothelial Growth Factor C; VEGFR: Vascular Endothelial Growth Factor Receptor; YY1: Ying Yang 1.

\section{Author contributions}

$\mathrm{AKB}$ and TKK conceived the project. AKB performed most of the in vitro and cellular assays. MK and AkshayB performed IHC staining experiments. SMK and AKB performed xenograft study. AdityB performed coactivation luciferase assay and assisted in xenograft studies. MV performed bioinformatic analysis of microarray data and network modeling. VJR performed bioinformatic analysis with RNA-seq data obtained from TCGA. AKB and TKK analyzed the data and wrote the manuscript.

\section{ACKNOWLEDGMENTS AND FUNDING}

TKK is recipient of JC Bose fellowship from Dept. of Science and technology, Govt. of India (SR/S2/JCB28/2010). This work was supported by funding from Dept. of Biotechnology, Govt. of India (BT/01/CEIB/10/III/01 and BT/PR17576/MED/30/1690/2016) and JNCASR, India.

\section{CONFLICTS OF INTEREST}

Authors declare that they have no conflicts of interest.

\section{REFERENCES}

1. Wang CC, Chen JJ, Yang PC. Multifunctional transcription factor YY1: a therapeutic target in human cancer? Expert Opin Ther Targets. 2006; 10:253-66. https://doi. org/10.1517/14728222.10.2.253. [PubMed]

2. Castellano G, Torrisi E, Ligresti G, Malaponte G, Militello L, Russo AE, McCubrey JA, Canevari S, Libra M. The involvement of the transcription factor Yin Yang 1 in cancer development and progression. Cell Cycle. 2009; 8:1367-72. https://doi.org/10.4161/cc.8.9.8314. [PubMed]

3. Shi J, Hao A, Zhang Q, Sui G. The role of YY1 in oncogenesis and its potential as a drug target in cancer therapies. Curr Cancer Drug Targets. 2015; 15:145-57. https://doi.org/10.2174/1568009615666150131124200. [PubMed]

4. Zaravinos A, Spandidos DA. Yin yang 1 expression in human tumors. Cell Cycle. 2010; 9:512-22. https://doi. org $/ 10.4161 / \mathrm{cc} \cdot 9.3 .10588$. [PubMed]

5. Ishii H, Hulett MD, Li JM, Santiago FS, Parish CR, Khachigian LM. Yin Yang-1 inhibits tumor cell growth and inhibits p21WAF1/Cip1 complex formation with cdk4 and cyclin D1. Int J Oncol. 2012; 40:1575-80. https://doi. org/10.3892/ijo.2012.1362. [PubMed]

6. Zhang Q, Stovall DB, Inoue K, Sui G. The oncogenic role of Yin Yang 1. Crit Rev Oncog. 2011; 16:163-97. https:// doi.org/10.1615/CritRevOncog.v16.i3-4.30. [PubMed]

7. Shi Y, Lee JS, Galvin KM. Everything you have ever wanted to know about Yin Yang 1.... Biochim Biophys Acta. 1997; 1332:F49-66. https://doi.org/10.1016/S0304419X(96)00044-3. [PubMed]

8. Wan M, Huang W, Kute TE, Miller LD, Zhang Q, Hatcher H, Wang J, Stovall DB, Russell GB, Cao PD, Deng Z, Wang W, Zhang Q, et al. Yin Yang 1 plays an essential role in breast cancer and negatively regulates p27. Am J Pathol. 2012; 180:2120-33. https://doi.org/10.1016/j. ajpath.2012.01.037. [PubMed]

9. Lee MH, Lahusen T, Wang RH, Xiao C, Xu X, Hwang YS, He WW, Shi Y, Deng CX. Yin Yang 1 positively regulates BRCA1 and inhibits mammary cancer formation. Oncogene. 2012; 31:116-27. https://doi.org/10.1038/ onc.2011.217. [PubMed]

10. Liu D, Zhang J, Wu Y, Shi G, Yuan H, Lu Z, Zhu Q, Wu P, Lu C, Guo F, Chen J, Jiang K, Miao Y. YY1 suppresses proliferation and migration of pancreatic ductal adenocarcinoma by regulating the CDKN3/MdM2/P53/ 
P21 signaling pathway. Int J Cancer. 2018; 142:1392-404. https://doi.org/10.1002/ijc.31173. [PubMed]

11. Zhang JJ, Zhu Y, Zhang XF, Liu DF, Wang Y, Yang C, Shi GD, Peng YP, Zhang K, Tian L, Miao Y, Jiang KR. Yin Yang-1 suppresses pancreatic ductal adenocarcinoma cell proliferation and tumor growth by regulating SOX2OTSOX2 axis. Cancer Lett. 2017; 408:144-54. https://doi. org/10.1016/i.canlet.2017.08.032. [PubMed]

12. Zhang JJ, Zhu Y, Xie KL, Peng YP, Tao JQ, Tang J, Li Z, Xu ZK, Dai CC, Qian ZY, Jiang KR, Wu JL, Gao WT, et al. Yin Yang-1 suppresses invasion and metastasis of pancreatic ductal adenocarcinoma by downregulating MMP10 in a MUC4/ErbB2/p38/MEF2C-dependent mechanism. Mol Cancer. 2014; 13:130. https://doi.org/10.1186/1476-459813-130. [PubMed]

13. Chinnappan D, Xiao D, Ratnasari A, Andry C, King TC, Weber HC. Transcription factor YY1 expression in human gastrointestinal cancer cells. Int J Oncol. 2009; 34:1417-23. https://doi.org/10.3892/ijo_00000270. [PubMed]

14. Luo J, Jiang X, Cao L, Dai K, Zhang S, Ge X, Zhou X, $\mathrm{Lu}$ X. Expression of YY1 correlates with progression and metastasis in esophageal squamous cell carcinomas. OncoTargets Ther. 2014; 7:1753-59. https://doi. org/10.2147/OTT.S66667. [PubMed]

15. Zhao G, Li Q, Wang A, Jiao J. YY1 regulates melanoma tumorigenesis through a miR-9 RYBP axis. J Exp Clin Cancer Res. 2015; 34:66. https://doi.org/10.1186/s13046015-0177-y. [PubMed]

16. Zhang N, Li X, Wu CW, Dong Y, Cai M, Mok MT, Wang H, Chen J, Ng SS, Chen M, Sung JJ, Yu J. microRNA-7 is a novel inhibitor of YY1 contributing to colorectal tumorigenesis. Oncogene. 2013; 32:5078-88. https://doi. org/10.1038/onc.2012.526. [PubMed]

17. Seligson D, Horvath S, Huerta-Yepez S, Hanna S, Garban H, Roberts A, Shi T, Liu X, Chia D, Goodglick L, Bonavida B. Expression of transcription factor Yin Yang 1 in prostate cancer. Int J Oncol. 2005; 27:131-41. https://doi. org/10.3892/ijo.27.1.131. [PubMed]

18. Kashyap V, Bonavida B. Role of YY1 in the pathogenesis of prostate cancer and correlation with bioinformatic data sets of gene expression. Genes Cancer. 2014; 5:71-83. https:// doi.org/10.18632/genesandcancer.12. [PubMed]

19. Tang S, Mishra M, Frazier DP, Moore ML, Inoue K, Deora R, Sui G, Dubey P. Positive and negative regulation of prostate stem cell antigen expression by Yin Yang 1 in prostate epithelial cell lines. PLoS One. 2012; 7:e35570. https://doi.org/10.1371/journal.pone.0035570. [PubMed]

20. Baritaki S, Katsman A, Chatterjee D, Yeung KC, Spandidos DA, Bonavida B. Regulation of tumor cell sensitivity to TRAIL-induced apoptosis by the metastatic suppressor Raf kinase inhibitor protein via Yin Yang 1 inhibition and death receptor 5 up-regulation. J Immunol. 2007; 179:5441-53. https://doi.org/10.4049/jimmunol.179.8.5441. [PubMed]

21. Huerta-Yepez S, Vega M, Garban H, Bonavida B. Involvement of the TNF-alpha autocrine-paracrine loop, via NF-kappaB and YY1, in the regulation of tumor cell resistance to Fas-induced apoptosis. Clin Immunol. 2006; 120:297-309. https://doi.org/10.1016/j.clim.2006.03.015. [PubMed]

22. Huerta-Yepez S, Vega M, Escoto-Chavez SE, Murdock B, Sakai T, Baritaki S, Bonavida B. Nitric oxide sensitizes tumor cells to TRAIL-induced apoptosis via inhibition of the DR5 transcription repressor Yin Yang 1. Nitric Oxide. 2009; 20:39-52. https://doi.org/10.1016/j.niox.2008.08.001. [PubMed]

23. Frietze S, Lupien M, Silver PA, Brown M. CARM1 regulates estrogen-stimulated breast cancer growth through up-regulation of E2F1. Cancer Res. 2008; 68:301-06. https://doi.org/10.1158/0008-5472.CAN-07-1983. [PubMed]

24. Habashy HO, Rakha EA, Ellis IO, Powe DG. The oestrogen receptor coactivator CARM1 has an oncogenic effect and is associated with poor prognosis in breast cancer. Breast Cancer Res Treat. 2013; 140:307-16. https://doi. org/10.1007/s10549-013-2614-y. [PubMed]

25. Wang L, Zhao Z, Meyer MB, Saha S, Yu M, Guo A, Wisinski KB, Huang W, Cai W, Pike JW, Yuan M, Ahlquist $\mathrm{P}, \mathrm{Xu}$ W. CARM1 methylates chromatin remodeling factor BAF155 to enhance tumor progression and metastasis. Cancer Cell. 2014; 25:21-36. https://doi.org/10.1016/j. ccr.2013.12.007. [PubMed]

26. Kim YR, Lee BK, Park RY, Nguyen NT, Bae JA, Kwon DD, Jung C. Differential CARM1 expression in prostate and colorectal cancers. BMC Cancer. 2010; 10:197. https:// doi.org/10.1186/1471-2407-10-197. [PubMed]

27. Ou CY, LaBonte MJ, Manegold PC, So AY, Ianculescu I, Gerke DS, Yamamoto KR, Ladner RD, Kahn M, Kim JH, Stallcup MR. A coactivator role of CARM1 in the dysregulation of $\beta$-catenin activity in colorectal cancer cell growth and gene expression. Mol Cancer Res. 2011; 9:660-70. https://doi.org/10.1158/1541-7786.MCR-100223. [PubMed]

28. Hong H, Kao C, Jeng MH, Eble JN, Koch MO, Gardner TA, Zhang S, Li L, Pan CX, Hu Z, MacLennan GT, Cheng L. Aberrant expression of CARM1, a transcriptional coactivator of androgen receptor, in the development of prostate carcinoma and androgen-independent status. Cancer. 2004; 101:83-89. https://doi.org/10.1002/cncr.20327. [PubMed]

29. Majumder S, Liu Y, Ford OH 3rd, Mohler JL, Whang YE. Involvement of arginine methyltransferase CARM1 in androgen receptor function and prostate cancer cell viability. Prostate. 2006; 66:1292-301. https://doi. org/10.1002/pros.20438. [PubMed]

30. Torre LA, Bray F, Siegel RL, Ferlay J, Lortet-Tieulent J, Jemal A. Global cancer statistics, 2012. CA Cancer J Clin. 2015; 65:87-108. https://doi.org/10.3322/caac.21262. [PubMed]

31. Fitzmaurice C, Dicker D, Pain A, Hamavid H, MoradiLakeh M, MacIntyre MF, Allen C, Hansen G, Woodbrook R, Wolfe C, Hamadeh RR, Moore A, Werdecker A, et al, and Global Burden of Disease Cancer Collaboration. The Global 
Burden of Cancer 2013. JAMA Oncol. 2015; 1:505-27. https://doi.org/10.1001/jamaoncol.2015.0735. [PubMed]

32. Petersen PE. Oral cancer prevention and controlthe approach of the World Health Organization. Oral Oncol. 2009; 45:454-60. https://doi.org/10.1016/j. oraloncology.2008.05.023. [PubMed]

33. Johnson N. Tobacco use and oral cancer: a global perspective. J Dent Educ. 2001; 65:328-39. [ [PubMed]

34. Riggs KJ, Saleque S, Wong KK, Merrell KT, Lee JS, Shi Y, Calame K. Yin-yang 1 activates the c-myc promoter. Mol Cell Biol. 1993; 13:7487-95. https://doi.org/10.1128/ MCB.13.12.7487. [ [PubMed]

35. de Nigris F, Crudele V, Giovane A, Casamassimi A, Giordano A, Garban HJ, Cacciatore F, Pentimalli F, Marquez-Garban DC, Petrillo A, Cito L, Sommese L, Fiore A, et al. CXCR4/YY1 inhibition impairs VEGF network and angiogenesis during malignancy. Proc Natl Acad Sci USA. 2010; 107:14484-89. https://doi.org/10.1073/ pnas.1008256107. [PubMed]

36. Sekimata M, Murakami-Sekimata A, Homma Y. CpG methylation prevents YY1-mediated transcriptional activation of the vimentin promoter. Biochem Biophys Res Commun. 2011; 414:767-72. https://doi.org/10.1016/j. bbrc.2011.09.155. [PubMed]

37. Lee JS, Galvin KM, See RH, Eckner R, Livingston D, Moran E, Shi Y. Relief of YY1 transcriptional repression by adenovirus E1A is mediated by E1A-associated protein p300. Genes Dev. 1995; 9:1188-98. https://doi.org/10.1101/ gad.9.10.1188. [PubMed]

38. Rezai-Zadeh N, Zhang X, Namour F, Fejer G, Wen YD, Yao YL, Gyory I, Wright K, Seto E. Targeted recruitment of a histone H4-specific methyltransferase by the transcription factor YY1. Genes Dev. 2003; 17:1019-29. https://doi. org $/ 10.1101 / \operatorname{gad} .1068003$. [PubMed]
39. Yao YL, Yang WM, Seto E. Regulation of transcription factor YY1 by acetylation and deacetylation. Mol Cell Biol. 2001; 21:5979-91. https://doi.org/10.1128/ MCB.21.17.5979-5991.2001. [PubMed]

40. Cheng D, Valente S, Castellano S, Sbardella G, Di Santo R, Costi R, Bedford MT, Mai A. Novel 3,5-bis(bromohydroxybenzylidene)piperidin-4-ones as coactivator-associated arginine methyltransferase 1 inhibitors: enzyme selectivity and cellular activity. J Med Chem. 2011; 54:4928-32. https://doi.org/10.1021/ jm200453n. [PubMed]

41. $\mathrm{Wu} \mathrm{J}, \mathrm{Xu}$ W. Histone H3R17me2a mark recruits human RNA polymerase-associated factor 1 complex to activate transcription. Proc Natl Acad Sci USA. 2012; 109:5675-80. https://doi.org/10.1073/pnas.1114905109. [PubMed]

42. R Core Team. R: A Language and Environment for Statistical Computing. R Foundation for Statistical Computing, Vienna, Austria. 2015. https://www.R-project.org.

43. Leroy B. Rarity: Calculation of Rarity Indices for Species and Assemblages of Species. R package version 1.3-6. 2016. https://CRAN.R-project.org/package=Rarity.

44. Peterson BG, Carl P. Performance Analytics: Econometric tools for performance and risk analysis. $\mathrm{R}$ package version 1.4.3541. 2014. https://CRAN.R-project.org/ package $=$ PerformanceAnalytics.

45. Tatake RJ, Rajaram N, Damle RN, Balsara B, Bhisey AN, Gangal SG. Establishment and characterization of four new squamous cell carcinoma cell lines derived from oral tumors. J Cancer Res Clin Oncol. 1990; 116:179-86. https://doi.org/10.1007/BF01612674. [PubMed] 